\title{
Subjectivity in Art History and Art Criticism
}

\author{
Eleni Gemtou \\ University of Athens, Greece
}

\begin{abstract}
Art history and art criticism belong in a wider sense to the humanities, whose aim is the interpretation and comprehension of human actions and intellectual work. Both fields draw their basic methodological tools from the hermeneutical tradition. Their central analytic category is comprehension (verstehen) that seeks to ascribe meaning to the spirit of these actions, or to works of art. The intention of the art historian is to analyse and integrate artistic works in a wider intellectual and social frame, while the aim of the art critic is to examine the values connected with artistic creations. Their roles are not always distinguishable, as analysis, comprehension, interpretation and evaluation often co-exist in the studies of both fields. However, the approach of the art historian should have a scientific character, aiming at objectively valid formulations, while the critic should give equal consideration to subjective factors, acknowledging international artistic values, often taking on the additional role of philosopher or theorist of art. In my paper I examine the varying degrees of subjectivity in the approaches of art historians and art critics. I give emphasis to the methods and language both use, while I approach the categories of artistic values (aesthetic, moral, cognitive) according to their subjective usage, but also to their role in the comprehension and evaluation of art. My conviction is that art history and art criticism are complementary activities, as the former creates fertile conditions for the latter's complete and essential evaluations.
\end{abstract}

\section{[Keywords: Subjectivity, Art, History, Criticism]}

Art history and art criticism belong in a wider sense to the humanities, the third largest scientific field, which has distinguishable purposes and methodologies from the other two, the analytic-empirical and the normative sciences ${ }^{1}$. The humanities aim at the interpretation and the comprehension of human actions and intellectual works by drawing their basic methodological tools from the hermeneutical tradition. Their central analytic category is comprehension (verstehen) that seeks to ascribe meaning by a kind of subjective transfer to the spirit of these actions, or to works of art $^{2}$. Contrary to the nomological approach of the analytical sciences and the regulative-deontological approach of the normative sciences, the humanities have an explicit valueorientation in their study of historical eras and cultural meanings.

Art history and art criticism are intellectual activities aiming at the study, comprehension and interpretation of artworks. Their basic difference concerns not only the recentness of their objects, but also their objectives: the art historian studies the works of the past and, by using hermeneutical methods, constructs systems on a historical and theoretical base, while the art critic is interested in contemporary art, which he analyzes and interprets with the aim of evaluating it critically. In this sense the work of the art critic functions as an important tool and a basic substructure for future historians.

The common point of historical and critical texts, which is the comprehension and interpretation of artworks, depends to a large extent on their author's intuition, perception and experience. Following, however conscientiously, their chosen methods and criteria, art historians (but also a large number of critics) attempt valid and intersubjective interpretations that will be

Rupkatha Journal on Interdisciplinary Studies in Humanities

Volume 2, Number 1, Special Issue, Visual Arts

URL of the Issue: http://rupkatha.com/rupkathav2n1.php

PDF URL of the article: http://rupkatha.com/V2/n1/SubjectivityinArtHistoryandArt Criticism.pdf

(c) www.rupkatha.com 
judged by the wider hermeneutical community in the course of time. For the construction of systems and theories they usually follow a scientific methodology, and for articulating their conclusions they use a strict, unsentimental language. On the other hand, many art critics evaluate artworks, holding as a criterion and expressing their own aesthetic experience.

This paper offers a meta-critical approach to critical and historical texts according to their degrees of subjectivity. Historical and critical texts are examined through three approaches, divided into the following sections:

I. Subjectivity as a direct intention of art historians and art critics.

II. The subjective factor in the analysis and interpretation of works of art.

III. Degrees of subjectivity in evaluative judgments.

\section{Subjectivity as a direct intention of art historians and art critics.}

The scientist, either belonging to the analytic-empirical faculty, or to the humanities, always begins his work from a personal motive in order to choose a field or an object to investigate. Inspiration, selection and composing of speculations are based largely on his creative imagination, hence they have subjective character. However, the analytical scientist is obliged in what follows to free himself of personal motives and ideologies in order to submit his theoretical constructions to strict empirical and logical controls with the aim of establishing objectivity. The purpose of the analytical sciences is the investigation and the explanation of the world can be achieved only if subjective factors have been minimized, as they may distort truth. Subjectivity, however, plays a decisive role in the humanities, which approach intellectual works and human action in an interpretive rather than explanatory manner.

Some art critics consciously incorporate their intentions into their texts, thus a meta-critical study must take them into serious consideration. In order to investigate the degrees of subjectivity, I distinguish three categories of texts ${ }^{3}$ : catalog essays for gallery and museum; reviews published in art and other journalistic magazines; and monographs on contemporary art, which have the character of philosophical essays.

In catalog essays, the critic, working on behalf of the gallery, museum or the artist, always articulates a positive evaluation. In his effort to accent the work and its creator he/she analyzes and interprets it, attempting to include it within a wider artistic era or tradition. In this framework, references and comparisons to the past or to modern recognized artists often function as tools for advancing the artist and his work.

The method of historicized criticism falls within the more general attempt to find a stable reference-framework in order to create rational evaluations. ${ }^{4}$ Until the middle of 19th cen., critics evaluated contemporary art in relation to works of certain past artists or styles: renaissance art of the Quattrocento was judged with reference to antiquity, while at the end of this period Raphael and Michelangelo functioned as reference points. In $18^{\text {th }}$ century France, after the intense conflicts between the partisans of Rubens and Poussin, a return once again to the models of ancient Greece and Rome has been observed. Within the conflict between "ancients and moderns," paragons were sought in the ancient arts or in the modern era. With the appearance of the avant-garde at the end of the 19th cen. and the promotion of the criterion of artistic newness as a standard of judgment, criticism based upon a historicized approach lost its basis. Soon, however, the 
system of artistic "modernism" was constructed, which posited a momentum generated by a sequence of works and which confronted $20^{\text {th }}$ century art. as a unit with a straight development along a definable trajectory. The value of avantgarde works was judged in relation, on the one hand, to recent modern works, and on the other, according to their contribution to the development of pioneering $\operatorname{art}^{5}$

Thus, comparisons of contemporary artworks to past standards, recent or distant, have their roots in the historicized criticism that bloomed between the 15th and the 19th cen. and today remains in use. Its aim is the promotion of contemporary works, by showing that they are equally important as past standards, but also that they play an important role as parts of the evolutionary chain of art. On the other hand, such comparisons give critical essays prestige and intersubjective validity: the critic doesn't express his subjective opinion, but by identifying a contemporary artwork with a timeless masterpiece, it's as if the critic is speaking on behalf of the wider art world.

The language in some catalog essays is poetic; it acquires literary value. Most catalog essays serve a double aim to promote the artist and to appear in themselves as autonomous "artworks" that give aesthetic satisfaction to the reader $^{6}$. In both cases the aim is to positively predispose the reader or the visitor to an exhibition with all that this entails. Their meta-critical study, however, should be based as much on the criterion of formal truth as on aesthetic criteria, because their validity and their intersubjective acceptance depend on both parameters.

Language is often used differently in reviews published in newspapers and magazines, as these serve a different aim: the critic doesn't work on behalf of the artist, but for an institution that presents and analyzes tendencies in modern and contemporary art. His intention is to record thorough and illuminating approaches to artworks, which contribute to their comprehension and evaluation by the audience.

Lately, there has been a tendency of avoiding evaluative judgments in journalistic reviews: emphasis is given instead to describing and interpreting the works in objective terms. It's a revival of the positivist critical tradition that has its roots in $19^{\text {th }}$ century Germany, where the sovereignty of the natural sciences and their methods prompted the extension of methodological monism to the humanities. However, explanatory approaches to artistic and intellectual works can only have a limited scope, as they aren't capable of determining them completely. A positivist review doesn't refer to the values that make a work interesting and capable of creating aesthetic experience; rather it describes it in the same way that a scientist would describe a natural phenomenon. But even in this case, language plays a decisive role: intelligently-selected words with a descriptive-ontological character simultaneously function as evaluative judgments ${ }^{7}$.

Monographs on modern and contemporary art often have the character of philosophical aesthetics essays. Changes in the 20th cen. rendered the existence of a theoretical and philosophical substructure necessary in order to redefine the art and justify avant-garde works ${ }^{8}$ Characteristic examples are The Transfiguration of the Commonplace by A. Danto, or The Originality of the Avant-Garde and other modernist myths by Rosalind Krauss . Originating in post-modern works the above texts treat questions that concern the definition of art and the possibilities of elevation to the artistic level of trivial or other aesthetic 
objects, (as for example the copies of authentic works by Sherrie Levine). The language used is direct, often narrative, with many examples from the artistic era and references to established philosophical theories, which justify personal positions. A philosophical essay begins with questions and speculations of a subjective character and aspires to answer them with logical and inductive arguments. The wider and longer-lasting the acceptance of the philosophical theory by philosophers, critics and readers, the more powerful its intersubjective character.

In art-historical monographs the writer also begins from personal motives: he selects his research field according to his subjective mood and preference for certain artists, movements or periods or because he judges that there is a gap in research that should be filled with new and original interpretations. In opposition, however, to certain art critics, the historian does not embed in his texts his feelings, but attempts to keep an essential distance from the research object, using a strict, systematic language without sentimental effusions and subjective judgments.

Two kinds of art-historical writings exist: narrative and theory. In narrative the art historian aims to make a story out of the interpreted works of art by arranging them in a certain order, deciding which work to include or to exclude and stressing some works over others. When constructing a theory, on the other hand, the art historian has an explanatory orientation and aims to include the works in a theoretical framework. Theories in art history seek for underlying principles that would both explain a work's specific historicity and provide sufficient continuity with the past, which would allow the art historian to explain historical transformations.

\section{The subjective factor in the analysis and interpretation of works of art}

I have distinguished two categories of texts according to the writer's intentions: texts that are characterized by the undiluted subjective positions of their writers (generally catalog essays), and those that use a scientific methodology and language for a more objective approach. Now, I will attempt a closer examination of the second group in order to show that, despite the intentions of the writers, the subjective factor plays a decisive role in these texts. Considering that interpretation is the common methodological tool in art history and art criticism, I will examine the iconographical and iconological theories of Erwin Panofsky, which are two of the most accepted and intersubjective hermeneutical methods, and still used by art historians as by art critics until today.

Before proceeding, however, I would like to clarify the criteria and the terminology that I will use to approach the above methods. I evaluate the content of a method on the criterion of "formal" truth, in order to show that it is valid. I have borrowed the term "formal" truth from the formal sciences of mathematics and logic, where truth does not refer to a correspondence to the objective world, but is the result of the logical structure of propositions. I make two approaches to the writings based on the criterion of subjectivity: first, an aesthetic approach that explores the way a theory is articulated (the style of the argumentation and language). According to this approach, a theory can be either subjective or objective. Second, an empirical approach, which explores the scope of the acceptance of a theory. According to this approach a theory can be either subjective (meaning that it was not accepted by anyone beyond its conceiver), or 
intersubjective (meaning that a large number of people accepted it and was probably influenced by it in the passage of time).

Panofsky aimed at the construction of general principles, by which all artworks could be analyzed and interpreted, independent of their time and local conditions. He considered the artwork not only as a direct result of the culture that gave rise to it, but also as the result of concrete tendencies of the human mind. Based on this double-faceted interpretation of artworks, Panofsky attempted to solve the hermeneutical problem $^{9}$ by claiming that completed interpretations are those that approach the work not only as a part of its historical and cultural era, but also as a human construction.

At the same time he approached the artistic work as a combination of form and content, rejecting the absolute formalistic hermeneutical system of Heinrich Woelfflin ${ }^{10}$. Woelfflin claimed that our sensory organs spontaneously give order to the chaotic world of phenomena, independent of the expressive and intellectual faculties of the brain. Panofsky believed that the classification of the sense data is an activity of the higher faculties of mind that are shaped according to the expressions and the content of the outside world. He did not accept the differentiation between form and content, as - contrary to Woelfflin he claimed that changes in style imply changes in the content of the work as well. Thus, valid formal principles could not result only through empirical observations ${ }^{11}$.

Within this framework he formulated a theory based on the internal formal qualities of the artistic work, which are the result of the relation of form and content $^{12}$. His system consisted of opposite pairs, plenitude / form, time / space, haptic / optic values, depth/surface and merging / divided forms ${ }^{13}$, which have not only a universal character and reflect the relation of the mind and the work of art $^{14}$, but they should also function as the means of controlling the relation of its form and content. Panofsky believed that by constructing an objective framework for the analysis of the artistic works subjective -psychological interpretations could be avoided, as they lead to privatized and emotionalized conceptions of art.

Panofsky was influenced as much by Warburg as by the hermeneutical tradition of the 19th century, which emphasized the distance of the interpreter from the interpreted object and underlined the huge difficulties that exists in interpreting artworks in the framework of their historical era. Panofsky disagreed with Heidegger ${ }^{15}$, who had stressed the subjective parameters of interpretation, by constructing control and balance systems restricting subjectivity.

With his article "Zum Problem der Beschreibung und Inhaltsdeutung von Werken der bildenden Kunst " ${ }^{16}$ Panofsky introduced the hermeneutical method in art history, based to some degree on Dilthey's theories. Both believed that valid interpretations are those whose every part is dependent on the interpretation of the whole ${ }^{17}$. Dilthey, though, had recognized a close connection between the work and its creator, interpreting it with the artist's intentions as the basic criterion. Panofsky, on the other hand, didn't aim at the localization of the artist's subjective intentions, as he considered it to be impossible, even though these might exist in the form of a written document by the artist. He conceived art history as a history of changing relations between mind and world. Art was for him a type of knowledge, in the framework of which the subject becomes objective, independent and public.

Panofsky's iconological method is a hermeneutical approach to art that is immediately connected to a "general history of the human spirit". It constitutes the 
third stage of his hermeneutical model ${ }^{18}$ that was completed in 1955. Its first stage is the pre-iconographical description (that constitutes the application of Woelfflin's formalistic theory) and its second stage is the iconographical analysis (influenced by Warburg ${ }^{19}$ ). Panofsky converged with Warburg in his conviction that for the right comprehension of an artwork essential conditions exist: the connection of the work to its culture as realized through the interpretation of its content in analogy with the content of literary works and the connection of its content to corresponding past iconographic types in the framework of a history of types. The third stage, the iconological interpretation ${ }^{20}$, aims at a deeper comprehension of the work beyond the conscious: Panofsky wanted to reveal the ways that works harmonize subjective impetuses and objective comprehension of the world. In order to ensure, however, the objectivity of interpretation, that is realized through a type of synthetic intuition and is determined to a large extent by the interpreter's psychology and his "Weltanschaungen", he proposes corrective principles such as general knowledge of cultural history and also a familiarity with what he regarded to be the human mind's essential tendencies throughout history.

In spite of these corrective principles, the history of the particular method reveals that the interpreters have often approached works according to their personal worldviews. Thus, for example, while Panofsky interprets Durer's "Melancholia I" in humanist terms, the German art historian Konrad Hoffmann (1978) includes the same work in medieval art and considers Durer as a pious aristocrat of this era and worldview ${ }^{21}$.

The existence of multiple interpretations doesn't refute the validity of Panofsky's theory, but reveals that despite his systematic efforts, the subjective factor remains decisive, as the interpreter cannot approach the work independently from his conception of the world and art. It's generally recognized, however, that his interpretations have shaped a tradition, have been established and have influenced many later art historians: this means that they have gained an intersubjective character ${ }^{22}$.

Panofsky's worldview though has determined his choices and his hermeneutical approaches. His basic research object was Italian renaissance art and the larger part of his theory was based on its fundamental principles. The notion of balance, used in relation to his five opposite pairs as a criterion for the evaluation and the nomination of "great" works of art, certainly emanates from the humanist critical tradition. All his choices are understood as consequences of his humanist bent: he indirectly absorbs Bellori's theory about the hierarchy in the categories of painting, with the allegorical and historical images dominating over landscapes, everyday scenes, portraits and still-lives, as all his analyses and interpretations concern the two first categories ${ }^{23}$. Another example is given by his interpretations of Duerer's work, especially those that investigate the relation of the artist to Italian renaissance $\mathrm{art}^{24}$. Panofsky considers Durer's work as a collision between the empirical northern tradition and the theoretical idealistic approach of the Italian School, which he definitely promotes as being supreme. As Sveltlana Alpers ${ }^{25}$ observes: "if we turn to Panofsky's masterful study of Durer, it's characteristic that he sees Durer as a kind of captive of the alien northern darkness struggling toward the southern light".

Panofskys' interpretations of Durer's work are connected with his humanist bent and have a subjective origi ${ }^{26}$. Their clarity, however, their internal cohesion, their logical sequence and their thorough sourcing render them valid, 
while the language used lends them an objective character, at least at a first reading. A critical reading, though demonstrates the intrusion of evaluative judgments that have a subjective base. Consider, for example, a simile he uses in his book "Early Netherlandish Painting "27 that relates the spectator's aesthetic experience when seeing Van Eyck's work: "From the sheer sensuous beauty of a genuine Jan van Eyck there emanates a strange fascination not unlike that which we experience when permitting ourselves to be hypnotized by precious stones or when looking into deep water". It's definitely a subjective judgment in the form of a simile that splits the objective and distanced language, and at the same time lends it aesthetic value.

\section{Degrees of subjectivity in evaluative judgments}

Evaluative judgments are those that refer to the values of the artworks and are included as much in the texts of art criticism, as in the narrations and the theories of art history. They cover the larger part of the description, the analysis and the interpretation of the works, as in art there exists an identification between facts and values. The "pure" facts of the artistic works are their dimensions, their materials, their date and the artist's signature, while form and content function as carriers of values: the world of an artistic work is an imaginary world of values, thoughts, wishes and sentiments (even though the content of the work is naturalistic, presenting a direct equivalence to reality). Objects or facts that in an empirical approach are evaluative neutral acquire in art symbolic character and evaluative significance.

Evaluative judgments play a sovereign role in the humanities, contrary to their position in the analytic-empirical sciences. There exists a clear differentiation between ontological-descriptive propositions and evaluative judgments, with the first having explicit informative character and the second expressing the attitude and subjective feelings of the one using them. An evaluative judgment cannot result from a fact, or as Hume remarks (1739-40): "an ought cannot be derived from an is ". Hence evaluative judgments do not constitute part of the scientific work in the analytical sciences that are directed to the explanation of reality. In the case of art, however, where facts and values are identified, evaluative judgments constitute a basic methodological tool of art history and art criticism.

At the beginning of my paper I claimed that the art historian interprets artworks in order to include them in a historical and theoretical system, while the art critic follows similar methods to evaluate artworks. This distinction does not concern the use of evaluative judgments that is common in both activities, but the intentions of the scholars who include themselves in one or the other occupation.

Nevertheless, two kinds of evaluations exist: first, evaluations which are the result of logical and critical procedures. These are based on complete interpretations and are justified by the interpreter's reasoned explanations; and refer to the significance of artworks not only in their historical era but also in the development of art in general. Thus, these neither emanate from the subjective preferences of the evaluator, nor are they connected with the criteria and dominating values of the evaluator's era. Such evaluative judgments are characteristic of art-historical writing and play an important role in art criticism. The second kind of evaluations derives from pure aesthetic approaches and it has a subjective character. Interpretation is not presupposed and the evaluator is not committed to giving logical reasons for his judgments. Such evaluative 
judgments dominate in catalog essays and some reviews, especially those belonging to the postmodern era, which functions as carriers of the energies created within and the impact of artworks upon the reviewer ${ }^{28}$.

The language used in historical and critical texts is often constituted of words that are metaphorical and comparative, characterizing the works not only in their own terms, but also in the terms of their creator's feelings and action, or of their recipient's and interpreter's reaction to them ${ }^{29}$. The last group of words is usually avoided by historians and critics who aim at a more distanced and objective approach to the works, but dominate in catalog essays and journalistic reviews.

The conviction that aesthetic values are facts connected with the form of the artistic works is explicitly formulated in the formalistic theories of Roger Fry and Clive Bell, in the framework of which formalism was changed from an hermeneutical method aiming at the comprehension of the work to a criterion of evaluation. Both scholars considered as appreciable only the works dominated by "pure form", as no margin could exist for "associated ideas" 30 . These theories are grounded in philosophical naturalism, in the framework of which aesthetic values are the intrinsic qualities of aesthetic objects and become perceptible through the senses.

Contrary to naturalism, idealism conceives aesthetic values as supernatural entities independent from the senses. They exist in the artistic work only as the reflections of the ideal values and the sensitive recipients conceive them intuitively. Influenced by Plato's philosophy, idealists cultivated a transcendental theory of beauty that has led to the creation of an idealized art from the Renaissance to the 19th cen. A third philosophical approach to the ontology of aesthetic values is subjectivism that does not accept their existence as elements of the natural world, but only as our intellectual or sentimental constructions.

The above philosophical theories that investigate the degrees of subjectivity in the way that we conceive values, are idealism defining them as ideal elements of the world completely independent from us; naturalism, as natural elements conceived through the senses, and subjectivism, as our intellectual constructions. All of these can lead to an extreme relativism that of course complicates a rational evaluation of art. The fact however, that during history there have existed constant and unchangeable aesthetic values lends them intersubjective force: even if we accept that values are human constructions, we cannot ignore the fact that there exists a common sense of beauty, a "sensus communis" in all humans that has lead to the admiration of concrete aesthetic facts and objects through the ages ${ }^{31}$. Sunsets, for example, will always be a subject of admiration to most humans, as also the great works of art of the past that, even in the modern era, where the traditional standards of beauty have been disputed, are recognized as brilliant by the larger part of the artworld. Our eyes will always be drawn by concrete combinations of colours or by the principles of symmetry and balance, even if different historical periods and art-institutions impose different models ${ }^{32}$. In this sense the degree of the subjectivity of aesthetic judgments is limited not only by the intersubjective character of concrete values that lends them universal force, but also by rules accepted as absolute in each era, either through important theoretical texts (eg. Aristotle's "Poetic"), or through the artistic tendencies that dominate and determine the notion of taste ${ }^{33}$. 
Moral values that exist in the content of visual works also have an intersubjective base. According to Hume's account of moral action in his "Treatise on Human Nature", all humans are naturally moved by a 'moral sense' or 'sympathy', which is essentially a capacity to share the feelings of happiness or misery of others. However, works of art should not be evaluated on moral criteria, but only on aesthetic ones. Moral judgments are included in the analysis and interpretation of artworks, but they shouldn't be considered as means of evaluation. Moral values in art should be approached in aesthetic terms: when we evaluate a work we shouldn't be interested in its content, but in the way content is expressed. Thus, when Dave Hickey ${ }^{34}$ evaluates the homosexual photographs of Robert Mapplethorpe he characterizes them as examples of "formal beauty" and doesn't touch upon moral parameters. He uses evaluative judgments that result from concrete aesthetic qualities of these photographs, as chiaroscuro and balance, which have an intersubjective and universal character, creating aesthetic satisfaction independent from the content.

The evaluations of artworks should also not be based on their cognitive values, since art doesn't aim at objective truth, but functions more as a motive for awakening and renewing ways of perceiving reality. An artwork can include cognitive and scientific elements, which however are presented in an aesthetic manner offering aesthetic satisfaction rather than enlargement of knowledge.

\section{Conclusions}

According to the above approaches to art criticism and art history on the criterion of subjectivity, both intellectual activities converge (with the exception of the catalog essays and some journalistic reviews). The analysis, the interpretation and the evaluation of artworks, as the common element of the texts, have to a large extent a subjective character, which however does not negate their validity or downgrade them to products of simple inspirational activities.

Art historians and art critics who seriously serve their occupation, investigate methods and corrective principles in order to ensure the validity of their texts, but also to limit the subjective aspects produced from unverifiable and idiosyncratic expressions. They systematically control the logical cohesion of their theories, while they interpret the works based on the sum of information they have about them and their era, investigate and reveal their interrelations and their integration in a historical, theoretical and cultural system. They evaluate them, finally, either directly or indirectly through the choice of words that reveal their hidden personal estimations.

The aesthetic-linguistic evaluations of the texts show their subjective/objective character, while empirical studies that concern their longstanding acceptance by the scientific community reveal their intersubjectivity. The underpinning theory, that the only valid interpretation is the one that emanates from the creator himself, cannot be valid. Even if it's confirmed by a personal oral or written testimony of the artist its acceptance as the only genuine and objective interpretation, would downgrade the uniqueness of the artistic phenomenon: the artwork is differentiated from natural objects or phenomena because, beyond its objective dimension, it has an indefinable intellectual depth with multiple levels of reading and interpretation. The relation between the work and the viewer is multidimensional and permanently altered, offering infinite possibilities of aesthetic satisfaction and enlargement of our thought. 


\section{End Notes}

${ }^{1}$ The sciences are divided into three categories, according to their methodologies and purposes: The analytical sciences aim at the objective truth and the explanation of the world. They apply a nomological approach in order to include their results in a framework of laws and regularities. To the analytical sciences belong the natural and social sciences (empirical sciences), and also mathematics and logic (formal sciences). The normative sciences research ways of regulating the world. They apply a regulative-deontological approach and their methodology is based on principles that imply criteria of right or wrong. The most significant normative sciences are Law and Ethics. The Humanities aim at the interpretation and comprehension of human actions and intellectual works by drawing their basic methodological tools from the hermeneutical tradition. Their central analytic category is "comprehension" ("verstehen") that seeks to ascribe meaning, in a kind of subjective transfer, to the spirit of these actions, or to works of art. They are valueoriented. To the Humanities belong, among others, Art History and Art Criticism.

${ }^{2}$ In traditional hermeneutics the interpreter has a participant's perspective rather than an observer's, as is the case for the scientific researcher in the natural and social sciences. However, Gadamer challenged this differentiation by applying hermeneutics in all cognitive regions and by perceiving interpretation as our only means of approaching and understanding the world. According to him interpretation is an ontological event reflecting the interaction between interpreter and interpreted object.

${ }^{3}$ James Elkins (in: What happened to Art Criticism, Prickly Paradigm Press, Chicago, 2003, pp.16-55) distinguishes seven categories of critical texts: the catalog essay, the academic treatise, cultural criticism, the conservative harangue, the philosophic essay, descriptive art criticism and poetic art criticism.

${ }^{4}$ Two kinds of intentional approach to artworks lead to their evaluation, a rational and an emotional one. The critic who prefers the rational approach is obliged to have certain fixed reference points, in order to make reasoned comparisons and justify his/her judgments on logical arguments. Such fixed reference points are universally recognized artworks of the distant or recent past, or intersubjective aesthetic values. Emotional evaluations are preferred by most postmodern critics, who judge the impact and the sensation of artworks over their meaning and interpretation. Susan Sontag in "Against Interpretation",1964, (in: A. Neill \& A. Ridley, The Philosophy of Art. Readings Ancient and Modern, Mc Graw Hill, Boston, 1995, pp. 457-465) claimed that intellectual approaches to art are against its expressional capabilities and proposed that art reviews should not include rational interpretations and evaluations, but rather should function as artworks in themselves, which carry forth the energies of the evaluated piece.

5 J. Ackermann, "On Judging Art without Absolutes", Critical Inquiry, vol. 5, No. 3, 1979, pp. 446-7.

In 2002, a survey conducted by the Columbia University National Arts Journalism Program found that judging art is the least popular goal among American art critics. The top three answers were first, describing artworks; second, providing historical context; and third, writing well (J. Elkins, What happened to Art Criticism, Prickly Paradigm Press, Chicago, 2003, pp. 12, 49).

${ }^{7}$ Elkins, 2003, p. 41.

${ }^{8}$ D. Carrier, "Philosophical Art Criticism", Leonardo, Vol. 19, No 2, 1986, pp. 170-174

${ }^{9}$ The hermeneutical problem in art history concerns the finding of basic principles that allow the incorporation of artworks in their historical framework and also in the general system of the development of art. Art theories try to answer both questions: what makes artworks historically specific, and what motivates changes in art. For a general introduction to art theories, s. M. Hatt \& Ch. Klonk, Art History. A critical Introduction to its Methods, Manchester University Press., Manchester, 2006. 
${ }^{10}$ H.Woelfflin (in: Principles of Art History: The Problem of the Development of Style in Later Art (trans. M.D. Hottinger), George Bell, London, 1932 [1915]) provided general descriptive terms, which would capture the development of artistic vision across countries and ages. He proposed a set of five opposite pairs: linear versus painterly, plane versus recession, closed versus open, multiplicity versus unity and absolute versus relative clarity.

${ }^{11}$ E. Panofsky, "Der Begriff des Kunstwollens", Zeitschrift fuer Aesthetik und allgemeine Kunstwissenschaft, 14, 1920, pp. 321-39.

${ }^{12}$ K. Moxey, "Panofsky's Concept on Iconology and the Problem of Interpretation in the History of Art", New Literary History, Vol. 17, No. 2, Interpretation and Culture, 1986, pp. 266-7.

${ }^{13}$ E. Panofsky E., "Ueber das Verhaeltnis der Kunstgeschichte zur Kunsttheorie", Zeitschrift fiir Aesthetik und allgemeine Kunstwissenschaft, XVIII, 1925, pp. $129 \mathrm{ff}$.

${ }^{14}$ The definition of these five opposite pairs is the result of the influence of Kant's theory on Panofsky, according to which humans don't have knowledge of the objects of the world as they are in themselves, but only of appearances. We perceive and understand the world through certain perception forms and categories that are common in all human minds. Panofsky attempted to show that our minds also organize aesthetic experience acquired by art through certain forms of perception.

${ }^{15}$ M. Heidegger, Kant und das Problem der Metaphysik, Vol. 3, 1930, in: Gesammtausgabe,ed. Friedrich Wilhelm von Herrmann et al., Klostermann, Frankfurt am Mai, 1975 .

${ }^{16}$ Logos 21, 1932, pp. 103-119.

17 This is the notion of the hermeneutical circle that refers -according to traditional hermeneutics- only to interpretations within the framework of the humanities. However, Heidegger and Gadamer radicalized it by promoting it as a feature of all knowledge and activity.

${ }_{18}$ O.Baetschmann (in: Einfuehrung in die kunstgeschichtliche Hermeneutik, Wissenschaftliche Buchgesellschaft, Darmstadt, pp.68-73) understands Panofsky's threestage model as a supplemental coexistence of scientific and hermeneutical methods. According to him, Panofsky aims, in his iconology, at the localisation of the causal relations determining artworks, and by seeing them as cultural symptoms he approaches them in scientific terms.

${ }^{19}$ A.Warburg called his method "critical iconology", central to which was the tracing of motifs through different cultures and visual forms. He used analogies between visual and literary motifs in order to connect artworks with their culture. As a corrective principle for avoiding subjective interpretations he applied the knowledge of the history of types. Panofsky adopted his method, as he also understood artworks as cultural symptoms and sought their deeper significance. Their main difference lies in the fact that Warburg perceived art as the articulation of social behavior and approached it in psychological terms, while Panofskys' approach was rather cognitive, as he understood art as the place where subjective drives and objective understanding of the world are connected (Hatt\&Klonk, 2006, pp.98-9).

${ }^{20}$ In his iconological theory Panofsky was influenced by Cassirer, who had applied Kant's cognitive categories in his critique of culture, defining them as "symbolic forms". Those were certain expressions of a culture that revealed the ways in which this culture understood the world. They were determined by a set of a priori functions of the human mind, but also were subject to historical change. The symbolic forms are parts of certain realms, such as science, art and religion. Panofsky adopted Cassirer's concept in his iconology, the goal of which was the recording of those symbolic forms which are integral parts of the artworks. A prerequisite of this was the knowledge of all cultural, social and spiritual circumstances that determine the belief system of each culture and era. According to Panofsky, perspective is a symbolic form which expresses the ways in which western civilization understood the notion of space from the Renaissance to the 
$19^{\text {th }}$ cen. Perspective is determined by the five opposite pairs of the human mind, but also is subject to historical change (E. Panofsky, Perspective as Symbolic Form (intro. \& trans. Chr. S. Wood), Zone Books, New York, 1991).

${ }_{22}^{21}$ Hatt \& Klonk, 2006, p.117.

22 D. Carrier, "Erwin Panofsky, Leo Steinberg, David Carrier: The Problem of Objectivity in Art Historical Interpretation", The Journal of Aesthetics and art Criticism, Vol. 47, No. 4, 1989, pp. 333-347.

${ }^{23}$ E. Panofsky E., Idea: a Concept in the History of Art, (tr.J.Peake), Columbia, S.C., 1968.

${ }^{24}$ E.Panofsky, Albrecht Duerer, 2 vols., Princeton, 1943.

${ }^{25}$ S. Alpers, "Is Art History?", Daedalus 106, No 3, Discoveries and Interpretations: Studies in Contemporary Scholarship, vol.I, 1977, pp. 1-13.

${ }_{26}^{26}$ Moxey, 1986, pp. 269-271.

${ }^{27}$ E. Panofsky, Early Netherlandish Painting: Its Origins and Character, 2 vols., 1953, Harvard University Press, Cambridge MA, p. 180.

${ }^{28}$ For the differences between art history and art criticism and especially for the changing course of criticism e.g in the magazine "Artforum" from the 1990s to today, D. Carrier, "Artcriticism-writing, Arthistory-writing, Artwriting", The Art Bulletin, Vol. 78, No. 3, 1996, pp.401-403.

${ }^{29}$ M. Baxandall, "The Language of Art History", New Literary History, Vol. 10, No. 3, Anniversary Issue: I., 1979, pp. 453-465.

${ }^{30}$ E. Prettejohn, Beauty \& Art, Oxford University Press, Oxford, 2005, p.175

${ }^{31}$ Kant in his "Critique of Judgment" ascribed to aesthetic judgments cognitive character by claiming that the basic types of the aesthetic experience, beauty and the sublime, are determined through his categories and forms of perception. Within this framework, a principle common to all human beings renders aesthetic experience necessary and changeless. It is called "common sense" and is defined as a common perception of beauty that constitutes an a priori principle of taste. Thus, the sense of beauty is intersubjective, functions objectively in our communication with each other, but is subjective in relation to reality (which -according to Kant- though existing is not supposed to be approached and comprehended independently of the categories and forms of perception of the mind). The notion of intersubjectivity in the reception of a theory is used differently, as it concerns consensus as the result of logical and empirical approaches to it and not of certain operations of the mind. See also, J. Elkins \& M. Newman, The State of Art Criticism, Routledge, New York \& London, 2008, pp. 38-4.

${ }^{32}$ Prettejohn, 2005, p. 181

${ }^{33}$ A. Tsugawa, "The Objectivity of Aesthetic Judgments", The Philosophical Review, Vol. 70, No. 1, 1961, pp. 3-22.

${ }^{34}$ D.Hickey, The Invisible Dragon: Essays on Beauty, Chicago University Press, Chicago, 2009, p.55.

Eleni Gemtou is Lecturer in the Department of Philosophy and History of Science, University of Athens, Greece. Email: egemtos@phs.uoa.gr 